\title{
The use of long leg calipers for paraplegic patients: a follow-up study of patients discharged 1973-82
}

\author{
Said Hawran and Fin Biering-Sørensen \\ Centre for Spinal Cord Injured, Rigshospitalet, The National University Hospital, Denmark
}

\begin{abstract}
We reviewed the medical records of 45 paraplegic patients discharged with long leg calipers, during the 10 year period 1973-82, from the Rehabilitation Hospital in Hornbæk, Denmark. A follow-up interview was carried out during 1993-94 for all 40 patients who were still alive. Thirty had complete paraplegia (seven women) and 10 had incomplete paraplegia (two women). At the follow-up interview only three were still using their calipers. The main reasons for giving up the use of calipers was, in $38 \%$, that it was too time consuming to put them on and take them off. For $22 \%$ the main reason was a fear of falling, while $19 \%$ reported that the calipers were impractical, as their hands had to be occupied in keeping balance and therefore could not be used for other purposes, including carrying items. The three paraplegic patients who did not totally give up the use of long leg calipers used them very little, at a maximum once a week. In contrast all 10 paraplegic patients who had been provided with a standing frame made use of this at least once a month. The majority of the remaining subjects were interested in having a standing frame. We therefore believe that a standing frame could be a good alternative to long leg calipers to facilitate standing for spinal cord injured patients.
\end{abstract}

Keywords: spinal cord injury; paraplegia; rehabilitation; long leg calipers; standing frame; walking; standing

\section{Introduction}

Many paraplegic patients during the primary rehabilitation period have a desire to obtain calipers to enable standing and walking. At the Rehabilitation Hospital, Hornbæk, Denmark up to 1982 it was a routine during the rehabilitation period that most paraplegic persons were required to learn to stand and walk with calipers during their rehabilitation (first admission). This policy has been changed in recent years, because of our experience that only a few of these patients actually made use of the calipers after being discharged. For this reason we carried out a follow-up study of patients who were discharged with long leg calipers.

\section{Method}

Our medical records were reviewed for all patients discharged with long leg calipers from our centre during the 10-year period 1973-1982. A follow-up was performed in 1993-94 either by telephone or when the patient came for routine assessment in the centre. The follow-up interview was carried out according to a fixed questionnaire.

The neurological level of lesion was determined as the most caudal segment with normal function at the

Correspondence: Dr Fin Biering-Sørensen, M.D., Ph.D., Centre for Spinal Cord Injured, Rigshospitalet, Havnevej 25, DK-3100 Hornbæk, Denmark time of discharge from the centre. Likewise the functional class ${ }^{1}$ was determined at the time of discharge from the primary rehabilitation period.

\section{Results}

During the period $1973-82,45$ patients were discharged with long leg calipers. At follow-up five were dead. The remaining 40 patients, 31 men and nine women, who were alive at follow-up were interviewed. Thirty had complete paraplegia (seven women), and 10 had incomplete paraplegia (two women).

After discharge from the primary rehabilitation period the long leg calipers were used at home for the periods shown in Table 1. Only three patients were still using their calipers, six patients never used the calipers after discharge.

Twenty two, that is the majority of the patients, had used the calipers to stand and walk; 11 patients only to stand; five patients have used the calipers only during rehabilitation in the hospital or at physiotherapy sessions after discharge; two of the patients had used the calipers only to walk on stairs.

The relation between the level of the neurological lesion (motor level) and the use of calipers and a standing frame is reported in Table 2. As expected the majority of the paraplegic patients provided with long leg calipers had lesions at or below T10 level. 
The main reasons for giving up the use of calipers are given in Table 3. More than one third felt that it took too much time to don and doff the calipers, and thus they lost interest in using them. Patients who were afraid to fall had often had several bad experiences from previous falls. Those who reported that the calipers were not practical for use at home, stressed that because their hands were occupied in retaining balance they could not be used for other purposes, such as carrying items.

Table 4 shows the job situation at follow-up in relation to the use of long leg calipers and standing frame.

Three paraplegic patients were still using the calipers at follow-up (two men and one woman): One man, 41 years of age living on a pension, had a complete (Frankel A) lesion at $\mathrm{L}_{1}$. He was $180 \mathrm{~cm}$ tall, weighing $65 \mathrm{~kg}$ and had a very muscular appearance. For 20 years he had used the calipers once a week for standing and walking. The other man, 33 years of age (height $173 \mathrm{~cm}$, weight $75 \mathrm{~kg}$ ) with a full-time job, had an incomplete (Frankel B) lesion at $\mathrm{L}_{2}$. During the last 13 years he had used the calipers for standing only once every 2 weeks. The woman was 35 years old and living on a pension. She had an incomplete (Frankel C) lesion at $T_{10}$. Her height was $162 \mathrm{~cm}$ and weight $60 \mathrm{~kg}$. During the last 14 years she had only used the calipers for walking on stairs once every 2 months.

Many of the patients who had never had a standing frame reported at interview that they would be interested to try this in the future. Among the ten individuals who actually had a standing frame, four used it daily, another four used it at least once a week, while the remaining two used it with intervals up to a month.

Table 1 The duration that long leg calipers were used after discharge from the Rehabilitation Centre

\begin{tabular}{lcc}
\hline & No. & $\%$ \\
\hline Never used at home & 6 & 15 \\
Used 0-6 months & 7 & 17.5 \\
Used 6-12 months & 8 & 20 \\
Used 1 -5 years & 9 & 22.5 \\
Used >5 years & 7 & 17.5 \\
Still in use at follow-up & 3 & 7.5 \\
Total & 40 & 100 \\
\hline
\end{tabular}

Table 2 Motor level of spinal cord lesion in relation to the number of patients using long leg calipers, and the use of a standing frame

\begin{tabular}{lccccc}
\hline & $\begin{array}{c}\text { Above } T_{5} \\
(\mathrm{n}=3)\end{array}$ & $\begin{array}{c}T_{6}-T_{9} \\
(\mathrm{n}=8)\end{array}$ & $\begin{array}{c}T_{10^{-}} L_{l} \\
(\mathrm{n}=26)\end{array}$ & $\begin{array}{c}L_{2}-L_{5} \\
(\mathrm{n}=3)\end{array}$ \\
\cline { 1 - 6 } Have used long leg calipers & 2 & 6 & 23 & 3 \\
Never used calipers at home & 1 & 2 & 3 & 0 \\
Have used a standing frame & 0 & 2 & 8 & 0 \\
Never used a standing frame & 3 & 6 & 18 & 3 \\
\hline
\end{tabular}

\section{Discussion}

The main reason for not using long leg calipers was that patients found them difficult to put on and take off. In addition, all of the patients said that they found it easier to get around in a wheelchair. The same conclusions were reached in the study by Coghlan et $a l^{2}$ A similar problem regarding the time necessary to put the device on and off has been found in using functional electrical stimulation. ${ }^{3}$

The calipers used during the study period (19731982) were made of strong metal and leather (each weighed $4 \mathrm{~kg}$ ) with Klentzak joints in the foot, a Schweizer lock at the knee and some with hip supporter depending on the level of the lesion. In our study the calipers weighed less (about $2 \frac{1}{2} \mathrm{~kg}$ for each one). However, taking the calipers on and off was still so time-consuming that many gave up using them for this reason. The other major reason for giving up the use of calipers was that their use was impractical, regarding use of their hands for other purposes. In addition, walking with calipers was a very demanding physical task, which also may cause patients to stop using them. A wheelchair was found to be much easier and more comfortable to use for most purposes. The problem of high energy expenditure has been previously emphasised in relation to the use of long leg braces ${ }^{4-6}$ for gait restoration.

Reviewing the three paraplegic patients who did not

Table 3 Reasons for giving up the use of long leg calipers

\begin{tabular}{lrr}
\hline & No. & $\%$ \\
\hline Troublesome to take on and off & 14 & 38 \\
Afraid of falling & 8 & 22 \\
Impractical, hands not free & 7 & 19 \\
Absence of motivation & 3 & 8 \\
Too heavy a load on the arms & 2 & 5 \\
Spasms & 2 & 5 \\
Too tight because of swollen legs & 1 & 3 \\
Total & 37 & 100 \\
\hline
\end{tabular}

Three patients were still using the long leg calipers at followup

Table 4 Job-situation at follow-up in relation to the use of long leg calipers after discharge and a standing frame

\begin{tabular}{lccc}
\hline & $\begin{array}{c}\text { Total } \\
\text { no. }\end{array}$ & Calipers & $\begin{array}{c}\text { Standing } \\
\text { frame }\end{array}$ \\
\hline Full time job $(\geqslant 37 \mathrm{~h} /$ week $)$ & 11 & 8 & 2 \\
Part time job $(\geqslant 20 \mathrm{~h} /$ week $)$ & 10 & 9 & 6 \\
Pension & 18 & 16 & 2 \\
Studying & 1 & 1 & 0 \\
Total & 40 & $34(85 \%)$ & $10(25 \%)$ \\
\hline
\end{tabular}

Six patients never used their long leg calipers at home after discharge 
completely give up the use of the long leg calipers, it has to be admitted that they used them very little, at most once a week by a very muscular man.

In contrast all 10 paraplegic patients who were provided with a standing frame used this at least monthly. The majority of the remaining subjects were interested in having a standing frame. We therefore think that a standing frame could be a good alternative to long leg calipers to facilitate standing for paraplegic patients.

\section{References}

1 Frankel HL, Hancock DO, Hyslop G et al. The value of postural reduction in the initial management of closed injuries in the spine with paraplegia and tetraplegia. Paraplegia 1969; 7: 179-192.
2 Coghlan JK, Robinson CE, Newmarch B, Jackson G. Lower extremity bracing in paraplegia - A follow-up study. Paraplegia 1980; 18: $25-33$

3 Krajl A, Bajd T, Turk R. Enhancement of gait restoration in spinal injured patients by functional electrical stimulation. Clin Orthop Rel Res 1988; 233: 34-43.

4 Marsolais EB, Edwards BG. Energy costs of walking and standing with functional neuromuscular stimulation and long leg braces. Arch Phys Med Rehabil 1988; 69: 243-249.

5 Waters RL, Lunsford BR. Energy cost of paraplegic locomotion. J Bone Joint Surg 1985; 67-A: 1245 - 1250.

6 Ragnarsson KT, Sell GH, McGarrity M, Ofir R. Pneumatic orthosis for paraplegic patients: Functional evaluation and prescription considerations. Arch Phys Med Rehabil 1975; 56: $479-483$. 